\title{
Será consistente a proposta de criação de uma união monetária no Mercosul?*
}

\author{
Will be consistent the proposal for the creation \\ of a monetary union in Mercosur?
}

FERNANDO FERRARI FILHO**

LUIZ FERNANDO DE PAULA***

RESUMO: Este artigo tem como objetivo discutir a proposta de união monetária no Mercosul à luz da teoria da Área Moeda Ótima (AMO). Mostra que não há evidências de que a convergência macroeconômica possa ser alcançada no Mercosul, uma vez que a área alcançou minimamente alguns critérios básicos definidos pela literatura da AMO.

PALAVRAS-CHAVE: Mercosul; união monetária; macroeconomia da união monetária.

ABSTRACT: This paper aims to discuss the proposal for monetary union in Mercosur in the light of the theory of Optimal Currency Area (OCA). It shows that there is no evidence that macroeconomic convergence can be reached in Mercosur, since the area only minimally achieved some basic criteria defined by the OCA literature.

KEYWORDS: Mercosur; monetary union; macroeconomics of monetary union.

JEL Classification: F2; F15; F45.

\section{INTRODUÇÃO}

Em março de 2001, o Mercosul completou dez anos ${ }^{1}$. Essa data, sem dúvida nenhuma, suscitaria, por si mesma, motivos para celebração. Todavia, a realidade econômico-social dos países que constituem o Mercosul mostra que há poucos

\footnotetext{
* Este texto foi escrito quando os autores eram pesquisadores visitantes do Centro de Estudos Brasileiros da Universidade de Oxford. Agradecemos, em particular, ao professor Leslie Bethell, diretor do Centro, pelo suporte e apoio dado para realização da pesquisa.

** Professor titular do Departamento de Economia da Universidade Federal do Rio Grande do Sul. e-mail: ferrari@ufrgs.br; Orcid: 0000-0001-5600-7058

*** Professor Adjunto da Faculdade de Economia da Universidade do Estado do Rio de Janeiro. e-mail: lfpaula@alternex.com.br; Orcid: 0000-0001-9770-516X.

${ }^{1}$ Mais especificamente, em 16 de março de 1991, os presidentes da Argentina, Brasil, Paraguai e Uruguai assinaram o Tratado de Assunção, criando, assim, o Mercosul, cujo objetivo precípuo era a criação de União Aduaneira na região.
} 
motivos para se celebrar o processo de integração nessa região. Por quê? Durante os últimos anos, o processo de integração no Mercosul tem sido caracterizado por turbulências econômicas: em janeiro de 1999, o real foi desvalorizado e, como resultado, trouxe dificuldades para os países do Mercosul, mais especificamente para a Argentina; e, recentemente, o colapso do Plano de Conversibilidade da Argentina tem causado instabilidade macroeconômica para os países do Mercosul, particularmente ao Brasil e Uruguai. Considerando essas turbulências, surge uma questão básica: qual é o futuro do Mercosul? Algumas respostas seguem a direção de que o futuro do Mercosul é tão-somente a consolidação de uma área de livre comércio; nesse sentido, a última etapa do processo de integração no Mercosul seria a inserção dos países membros dessa região no Acordo de Livre Comércio das Américas (ALCA). Outras respostas são direcionadas para o argumento de que somente uma unificação monetária no Mercosul é capaz de criar uma nova estrutura econômica para disciplinar as políticas fiscal e monetária dos governos do Mercosul, prevenindo, por conseguinte, as crises monetário-cambiais. Ao mesmo tempo, essa unificação permitiria um aprofundamento da integração econômica da região.

Até recentemente, as evidências mostravam que o processo de integração no Mercosul caminhava na direção de se criar uma unificação monetária: em 1998, por exemplo, o então presidente da Argentina, Carlos Menem, propôs a "dolarização" do Mercosul²; em 1999, a reunião anual do Comitê do Mercosul sinalizou a possibilidade de se introduzir, em um futuro ainda indefinido, uma moeda única para os países do Mercosul; e em dezembro de 2000 os presidentes do Mercosul aprovaram alguns critérios de convergência macroeconômica, em que os países membros do Mercosul teriam, em princípio, que harmonizar metas relacionadas às taxas de inflação, aos déficits fiscais e às dívidas públicas, assim como aos saldos de transações correntes do balanço de pagamentos ${ }^{3}$. Entretanto, com a crise econômica e social da Argentina em 2001, cujo resultado foi o colapso do Plano de Conversibilidade no início de 2002, surgiram alguns problemas para o Mercosul que não somente postergam qualquer proposição de integração monetária na região, como também acabam colocando em dúvida a própria dinâmica de curto prazo do processo de integração de seus países membros.

Dentro desse contexto, o objetivo do presente artigo consiste em mostrar a inconsistência da proposta de se criar uma união monetária no Mercosul, como etapa final do processo de integração econômica dessa região ${ }^{4}$. Para tanto, o artigo

\footnotetext{
${ }^{2}$ É importante mencionar que a proposição de Carlos Menem tinha como alicerce a idéia de que o sistema de currency board introduzido na Argentina no qual o peso, constitucionalmente, estava ancorado ao dólar, na cotação de 1 (um) por 1 (um) permaneceria como regime monetário argentino. Em outras palavras, a proposição de dolarização das economias do Mercosul atendia os interesses imediatos da Argentina de manutenção do Plano de Conversibilidade.

${ }^{3}$ A propósito, os referidos critérios foram chamados de "Pequeno Maastricht para o Mercosul".

${ }^{4}$ Em termos gerais, um processo de integração econômica tem uma seqüência natural, qual seja: ele iniciase com o estabelecimento de uma área de livre-comércio, visando criar uma tarifa externa comum para os partícipes do processo de integração e termina com a criação de um mercado comum no qual
} 
está dividido em três seções, além desta breve introdução. Na seção seguinte, apresenta-se um breve survey sobre a literatura de Áreas Monetárias Ótimas (AMO), uma vez que os argumentos sobre união monetária têm como referência teórica a AMO.

Em seguida, visto que o debate acadêmico acerca da criação de uma união monetária no Mercosul — Edwards, 1998, Giambiagi e Rigolon, 1999, e Giambiagi, 1999, são exemplos representativos desse - está baseado na experiência da União Monetária Européia (UME) e tem como inspiração teórica a AMO, mostra-se que não há evidência empírica de convergência macroeconômica no Mercosul e, por conseguinte, uma proposta de unificação monetária para essa região é por demais prematura. Por fim, a seção final sumariza os argumentos desenvolvidos no texto e conclui.

\section{UM BREVE SURVEY SOBRE A AMO}

No início dos anos 1960, Mundell (1961) formulou uma estrutura teórica de arranjo cambial ótimo que se tornou referência para a teoria da AMO. Naquela ocasião, Mundell rejeitou a idéia de flexibilidade da taxa de câmbio como instrumento eficiente para estabilizar os desequilíbrios de uma economia - isto é, manter, ao mesmo tempo, equilíbrio externo e pleno emprego - e centrou as atenções em um regime cambial no qual dois (ou mais) países fixam a taxa de câmbio entre eles, como condição para manter a estabilidade dos preços relativos e promover a integração da região.

Partindo do pressuposto de que o objetivo principal da política econômica consiste em manter o equilíbrio externo em um contexto de pleno emprego, a análise de Mundell argumentava que o grau de mobilidade dos fatores de produção - tanto trabalho quanto capital - constituir-se-ia em uma importante questão para determinar o regime cambial ótimo. Nesse contexto, Mundell concluiu que o limite de uma AMO deveria estar associado ao trade-off entre mobilidade dos fatores de produção e o tamanho da região.

Desde então, a idéia de estabelecer uma moeda única para dois ou mais países, admitindo que eles tenham características comuns, tem sido parte do debate acadêmico. McKinnon (1963) e Kenen (1969), por exemplo, apresentaram importantes contribuições à análise pioneira de Mundell.

McKinnon enfatizou a relevância do tamanho e abertura das economias - isto é, a relação entre a produção de tradables e non-tradables de um país - para determinar a eficiência do sistema cambial. De acordo com o autor, quanto maior e mais aberta a economia de um país, mais eficiente é o sistema de câmbio fixo para restaurar o equilíbrio externo e manter a estabilidade interna. Nas palavras de McKinnon,

os países membros têm que harmonizar suas políticas macroeconômicas e permitir a livre circulação dos fatores de produção. 
"if we move across the spectrum from closed to open economies, flexible exchange rates become both less effective as a control device for external balance and more damaging to internal price-level stability" (McKinnon, 1963: 719).

Kenen (1969), corroborando a idéia de Mundell relacionada ao grau de mobilidade dos fatores de produção como uma condição importante para a escolha do regime cambial ótimo, argumentou que esse dependeria, também, do grau de mobilidade dos fatores de produção intra-indústria. Para ele, quanto maior a diversificação de uma economia em termos de atividade produtiva e capacidade ocupacional, menores são os seus custos de desemprego e inflacionário decorrentes de choques econômicos imprevistos. Em outras palavras, as características estruturais de uma economia são fundamentais para determinar a escolha do regime de câmbio ótimo, visto que são essas que capacitam a economia a absorver choques exógenos.

Em resumo, conforme a $\mathrm{AMO}$, as condições econômicas para a adoção de uma união monetária são as seguintes: (i) o tamanho e a abertura da economia envolvida no comércio internacional; (ii) o livre movimento dos fatores de produção capital e trabalho; (iii) o elevado nível do comércio intra-regional e da diversidade da produção; e (iv) a capacidade de ajustamento da economia face às suscetibilidades de choques assimétricos. Em outras palavras, a introdução de uma moeda única em uma região específica depende do grau de integração regional do mercado dessa região. Eichengreen (1998: 14), por exemplo, afirma que "optimum currency area theory predicts that exchange rate should rise with the asymmetric of output movements, the dissimilarity of exports and country size [...] while falling with trade linkages".

Em geral, a análise da AMO mostra que um regime de câmbio fixo é mais apropriado para países que são completamente integrados. Nesse contexto, a decisão de um país inserir-se em um processo de unificação monetária é determinada pelas vantagens e desvantagens que esse país tem em decorrência de ter (ou não) políticas fiscal e monetária centralizadas para promover a integração econômica, assim como da capacidade de adoção de políticas de coordenação macroeconômica.

Sob essas circunstâncias, quais são as vantagens e desvantagens de um país quando ele decide juntar-se a uma união monetária, tendo como referência a AMO? Os benefícios econômicos de uma união monetária estão relacionados mais à eficiência microeconômica, tais como: (i) a taxa de inflação na união monetária em geral é significativamente menor; (ii) os custos de transação e de hedge dos agentes em relação aos riscos de variação da taxa de câmbio são reduzidos ou eliminados; (iii) a eliminação das taxas alfandegárias harmoniza, tudo mais constante, os preços dos produtos da economia, colocando-os em linha com os preços internacionais (lei do preço único); (iv) as barreiras sobre mobilidade dos fatores de produção são removidas; e (v) a integração regional é estimulada. Por outro lado, a principal razão pela qual um país deve evitar inserir-se em uma união monetária é a seguinte: o país prefere operacionalizar de forma independente sua política econômica para promover o crescimento econômico e o equilíbrio do balanço de pagamentos, tendo a taxa de câmbio como um instrumento de política econômica.

Para sumarizar a idéia central desta seção, a discussão sobre AMO mostra que, 
antes de um país decidir participar (ou não) de uma união monetária, ele tem que analisar os prós e contras que decorrem da política econômica a ser implementada. Em outras palavras, a decisão do país de juntar-se a uma união monetária cria o seguinte trade-off: ganhos microeconômicos resultantes do processo de coordenação da política econômica vis-à-vis perdas macroeconômicas como conseqüência das restrições que as autoridades monetárias passam a ter no sentido de operacionalizar de forma independente a política econômica.

\section{O MERCOSUL É UMA AMO? HÁ CONVERGÊNCIA MACROECONÔMICA NO MERCOSUL?}

A proposição de se criar uma união monetária para o Mercosul é claramente inspirada na experiência da $\mathrm{UME}^{5}$, como tem sido reconhecido pelos autores que defendem essa idéia (Giambiagi e Rigolon, 1999, e Giambiagi, 1999), assim como tem suporte teórico na AMO (Mundell, 1961; McKinnon, 1963, e Kenen, 1969).

Giambiagi (1999), por exemplo, acredita que, entre 2010 e 2015, o Mercosul estaria em condições de adotar uma moeda única. Segundo ele, "the answer to the question 'Does monetary union in Mercosur make sense?' is 'Yes'. However, the answer to the question 'Is this a viable option in the short term? is obviously 'No'" (Giambiagi, 1999: 31).

Indo nessa direção, Giambiagi apresenta uma proposta de Agenda de Trabalho que estabelece um cronograma para implantação de uma união monetária no Mercosul. Conforme o autor, essa Agenda "aim[s] [...] that [...] the four Mercosur countries would: first, have an inflation close to international levels; second, respect the same public sector deficit established in Maastricht for the euro countries; and third, have certain modest external disequilibria goals" (Ibidem: 30, ênfase adicionada).

Conforme a proposta de Giambiagi (Ibidem: 27-31), bem como levando em consideração as metas de convergência macroeconômica aprovadas, em dezembro de 2000, pelos presidentes dos países partícipes do Mercosul, as condições requeridas para que os países do Mercosul, ou qualquer outro país da América do Sul, sejam capazes de fazer parte de uma possível união monetária na região devem ser as seguintes: (i) criação de uma área de livre-comércio; (ii) os países devem harmonizar as políticas macroeconômicas; (iii) os países não podem desvalorizar suas taxas de câmbio, bem como eles devem mantê-las dentro de uma margem normal determinada, por exemplo, pelo banco central regional; (iv) a taxa anual de inflação de um determinado país não pode ser superior a 3,0\%; (v) os países não podem ter excessivos déficits fiscais - mais especificamente, esses não podem ser superior a 3,0\% do PIB; (vi) a dívida líquida pública de um país membro não pode exceder

\footnotetext{
${ }^{5}$ Para uma análise crítica do uso do modelo da UME como inspiração para o Mercosul, ver Arestis et al. (2001).
} 
40,0\% do PIB; e (vii) os países não podem apresentar uma relação transações correntes/PIB acima de 3,0\%.

Analisando especificamente o documento pertinente aos critérios de convergência macroeconômica, aprovado em dezembro de 2000 pelos presidentes do Mercosul durante o encontro regional anual do Mercosul, percebe-se que esse enfatiza que se os países, em um determinado ano, incorrerem em desvios em relação aos critérios pré-estabelecidos, então eles terão que adotar medidas corretivas para alcançar os critérios de convergência macroeconômica.

Como observado na seção anterior, tomando como base a literatura da AMO, existem algumas pré-condições para que os países passem a aderir a uma união monetária, quais sejam: (i) os processos de integração comercial e financeiro entre os países devem ser intensificados; (ii) a mobilidade dos fatores de produção deve ser dinamizada; e (iii) as variáveis macroeconômicas dos países membros devem convergir. Em suma, a criação de uma moeda única para determinada região depende do quão integrada é o mercado regional.

Nesse particular, a evidência mostra que o processo de integração comercial e financeira nos países do Mercosul é muito incipiente. Os dados pertinentes às exportações intra-regionais da Argentina, Brasil, Paraguai e Uruguai mostram que esses países ainda exportam para a região menos de 2,0\% do PIB global do Mercosul ${ }^{6}$. Além do mais, o grau de abertura dos países do Mercosul é ainda muito baixo, bem como o tamanho de sua economia envolvida no PIB mundial é tão-somente $4,0 \%{ }^{7}$.

Quando consideramos a mobilidade dos fatores de produção no Mercosul, percebe-se que, em primeiro lugar, há uma assimetria de mobilidade de capital para os países. O Uruguai, como sabemos, implementou, há muito tempo, a abertura do mercado financeiro ao capital externo como parte de sua estratégia para desenvolver um centro financeiro internacional. A Argentina, ao longo dos anos 1990, não tinha nenhuma restrição ao capital internacional, muito pelo contrário, visto que faz parte de sua política estratégica era obter credibilidade internacional para manter o regime de currency board. Recentemente, todavia, face ao colapso do Plano de Conversibilidade e à moratória externa, o controle de fluxo de capital internacional passou a fazer parte da estratégia argentina de curto prazo. O Brasil, por sua vez, com seu regime de câmbio flexível, é capaz de implementar algum tipo

\footnotetext{
${ }^{6}$ Apesar do volume de comércio entre os países do Mercosul ter triplicado entre 1991 e 2000, nesse último ano, por exemplo, a relação entre exportações FOB da Argentina, Brasil, Paraguai e Uruguai direcionadas para o Mercosul e o PIB global dessa região era de aproximadamente 1,9\% (US\$ 17,6 bilhões de exportações intra-regionais para um PIB global de cerca de US\$ 914,9 bilhões). Por outro lado, as importações intra-regionais dos países do Mercosul representaram, em 2000, 20,3\% do volume total das exportações globais dos países do Mercosul (US\$ 17,6 bilhões em relação a US\$ 86,6 bilhões), conforme cálculos a partir de dados obtidos junto a CEPAL, 2001.

${ }^{7}$ Em particular, Brasil e Argentina, apesar do recente crescimento de seu comércio intra-regional, são economias muito fechadas em termos de comércio internacional. Uruguai e Paraguai, por sua vez, são economias mais abertas, porém têm uma participação relativa pequena na economia global do Mercosul.
} 
de controle de capitais. O Paraguai apenas recentemente liberou seu mercado financeiro.

Em segundo lugar, no que diz respeito à mobilidade da mão-de-obra no Mercosul, essa é muito baixa. Em particular, a mobilidade do fator trabalho entre os dois principais países do bloco - Brasil e Argentina - tem sido historicamente muito pequena, e sua tendência não tem sido modificada ao longo dos últimos anos. $\mathrm{Na}$ prática, não é muito difícil apresentar razões que fazem com que a mobilidade de trabalho seja relativamente pequena na área do Mercosul: por um lado, há diferenças tecnológicas e profissionais entre os trabalhadores da região; por outro, o mercado de trabalho nos países do Mercosul é muito regulado.

Retornando à agenda do Mercosul proposta por Giambiagi, ao focarmos a atenção no primeiro ponto - criação de uma área de livre-comércio —, observa-se que o Mercosul está longe de se constituir em uma área de livre-comércio, devido, principalmente, aos conflitos comerciais entre Argentina e Brasil. O próprio Giambiagi reconhece que há uma deterioração nas relações comerciais dentro da área do Mercosul: "problems such as those that affected the sugar sector in Argentina, or the protest against Brazilian phytosanitary controls [...] [A]fter the devaluation of the real, Argentine producers made [...] demands, such as the introduction of a specific tariff against Brazilian goods, safeguard measures and the establishment of quotas" (Ibidem: 20).

Resgatando os pontos relacionados aos critérios de definição e mensuração das principais variáveis macroeconômicas e de manutenção de uma taxa de câmbio mais estável entre os países do Mercosul, é possível perceber que Argentina, Brasil, Paraguai e Uruguai ainda têm diferentes regimes monetários e cambiais. O Uruguai, desde o início dos anos 1990, tem adotado um regime de crawling peg no qual o peso flutua conforme os objetivos de estabilização de preços. A Argentina, após ter adotado ao longo dos anos 1990 um sistema clássico de currency board, vinculando o peso ao dólar, na cotação de 1 (um) por 1 (um), recentemente adotou um sistema de câmbio flutuante. O Brasil, a partir de 1999, adotou um regime de câmbio flexível, concomitantemente com um regime de metas de inflação. O Paraguai, por sua vez, ao longo dos últimos anos, está implementando uma política de desvalorização administrada de sua moeda, guarani. Nesse sentido, uma vez que os regimes cambiais dos países do Mercosul ainda diferem, é pouco provável que haja condições para se ter - a curto ou médio prazo - uma coordenação macroeconômica e, eventualmente, uma união monetária na região. Fanelli (2000:3), por exemplo, argumenta que "[e]s practicamente imposible que dos países avancen en la coordinación de sus políticas macroeconómicas ignorando el tipo de régimen cambiario que cada uno posee".

No que diz respeito às metas de inflação, apesar de esse ser um dos poucos critérios em que ocorre, pelo menos recentemente, uma certa convergência, principalmente após a implementação de políticas de estabilização semelhantes nos países da região, os países do Mercosul, com exceção da Argentina nos anos 1990, ainda têm inflações acima de 3,0\%. Além do mais, o critério de 3,0\% de tolerância máxima para a inflação de cada país do Mercosul é muito ambicioso, quando se 
leva em consideração o passado de alta inflação dos países dessa região, conforme nos mostra a Tabela 1 .

As estatísticas relativas ao déficit fiscal nos países do Mercosul mostram que (i) o déficit nominal no Brasil, desde 1995, tem sido maior do que 3,0\% do PIB; (ii) a Argentina tem apresentado déficits nominais menores do que o critério proposto, porém eles têm sido crescentes; e (iii) os déficits nominais no Paraguai e Uruguai, em período recente, somente foram superiores a 3,0\% do PIB em 2000 e 1999 e 2000 , respectivamente. Por outro lado, considerando-se o critério dívida líquida pública/PIB, no qual é suposto que essa relação seja inferior a 40,0\%, as estatísticas mostram que: (i) entre 1991 e 2000, tanto Paraguai quanto Uruguai apresentaram uma relação abaixo do referido valor, porém essa relação está crescendo no Paraguai e tem se mantido estável no Uruguai; (ii) na Argentina essa relação está crescendo e nos dois últimos anos foi superior ao valor proposto de 40,0\%; e (iii) essa relação no Brasil, durante o período $1998-2000$, foi superior a $40,0 \%{ }^{8}$, com a agravante de que ela está crescendo acentuadamente nos últimos anos.

É importante salientar que quaisquer critérios que disciplinam política fiscal implicam na impossibilidade de se utilizar política fiscal de forma ativa para compensar os problemas de desemprego causados por assimetria de choques. No caso do Mercosul, face às fragilidades externas dos países e as necessidades de ingresso de capitais externos, a austeridade fiscal é bastante rígida, fazendo, portanto, com que a política fiscal não possa ser utilizada como instrumento contra-cíclico.

Por fim, quando analisamos as estatísticas pertinentes aos desequilíbrios externos dos países do Mercosul, é possível observar que, entre 1997 e 2000, a relação média entre déficit de transações correntes e PIB da Argentina, Brasil, Paraguai e Uruguai foi, respectivamente, $4,1 \%, 4,2 \%, 1,8 \%$ e $2,3 \%$. Além do mais, observando-se os casos argentino e brasileiro, constata-se que, desde 1996, há uma tendência de deterioração dessa relação, principalmente devido ao crescimento da dívida externa desses países.

\section{CONCLUSÃO}

Como se observou no artigo, a proposta de criação de uma unificação monetária para o Mercosul tem como inspiração teórica a AMO. Nossa análise realizada no texto mostra que não há evidência de convergência macroeconômica no Mercosul, e, portanto, essa região não apresenta características de uma AMO. Por um lado, os problemas do Mercosul são tão complexos que é difícil acreditar que, no longo prazo, alguma convergência possa ser alcançada. De outro lado, uma vez que o Mercosul ainda não alcançou o estágio de mercado comum, é muito cedo propor uma união monetária para a região. Nessa direção, Eichengreen (1999: 9) argumenta que "supplementing regional integration with an initiative to stabilize the

\footnotetext{
${ }^{8}$ Os referidos dados são encontrados na Tabela 1.
} 
exchange rate or move toward a single currency becomes more urgent when integration moves beyond the establishment of a free trade area or a custom union to the creation of a deeply integrated market" e, continua o autor, "monetary union makes sense as a solution to MERCOSUR's exchange regime rate problem only if it is part of a significantly deeper project" (Ibidem: 34$)$.

Concluindo, considerando que o Mercosul está longe de ser uma área de livre comércio, a discussão em torno da criação de uma união monetária para o Mercosul é prematura, carecendo, portanto, de sentido. Em suma, a proposta de unificação monetária para o Mercosul parece ser, parafraseando Roberto Schwarz, mais uma dessas "idéias fora de lugar".

\section{REFERÊNCIAS BIBLIOGRÁFICAS}

ARESTIS, P.; FERRARI-FILHO, F.; PAULA, L.F.; SAWYER, M. (2001). "The Euro and the EMU: lessons for MERCOSUR". Paper presented to the Workshop entitled "Towards macroeconomic convergence in MERCOSUR? Lessons from the European Monetary Union” and held at St Antony's College, University of Oxford, 12 de Junho. CEPAL/ECLAC. www.cepal.org.

EDWARDS, S. (1998). "How about a single currency to Mercosur?” Wall Street Journal, 28 de Agosto, p. A11.

EICHENGREEN, B. (1999). Does Mercosur need a single currency? http://papers.nber.org/papers/ w6821.

FANELLI, J.M. (2000). Coordinación macroeconómica en el Mercosur: marco analítico y hechos estilizados. CEDES. Buenos Aires, Novembro, 25 páginas.

GIAMBIAGI, F. (1999). Mercosur: why does monetary union make sense in the long run? Ensaios $B N D E S$, 12, Dezembro, Rio de Janeiro.

GIAMBIAGI, F.; RIGOLON, F. (1999). Áreas monetárias ótimas: teoria, unificação monetária européia e aplicações para o Mercosul. Economia Aplicada, 3(1):79-99, Janeiro-Março.

INTER-AMERICAN DEVELOPMENT BANK. www.iadb.org.

KENEN, P. (1969). “The theory of optimum currency areas: an eclectic view”. In: MUNDELL, R.; SWOBODA, A. (eds.). Monetary problems of the international economy. Chicago: University of Chicago Press, pp. 41-60.

MCKINNON, R.I. (1963). Optimum currency areas. American Economic Review, 53(4):717-25, Setembro. MERCOSUL. www.mercosul.org.

MUNDELL, R. (1961). The theory of optimum currency areas. American Economic Review, 51(4): 65765 , Setembro. 
Tabela 1: Critérios de Convergência - Dados do Mercosul

\begin{tabular}{|c|c|c|c|c|c|c|c|c|}
\hline \multirow[t]{2}{*}{ Ano } & \multicolumn{4}{|c|}{ Inflação (Preços ao consumidor) } & \multicolumn{4}{|c|}{ Déficit-Superávit Público/PIB1 } \\
\hline & Argentina & Brasil & Paraguai & Uruguai & Argentina & Brasil & Paraguai & Uruguai \\
\hline 1991 & 84,0 & 480,2 & 11,8 & 81,3 & $-0,5$ & $-0,1$ & $-0,2$ & 1,2 \\
\hline 1992 & 17,6 & 1157,8 & 17,8 & 59,0 & 0,6 & $-1,8$ & $-0,6$ & 1,5 \\
\hline 1993 & 7,4 & 2708,2 & 20,4 & 52,9 & 1,2 & $-0,7$ & 0,4 & $-0,6$ \\
\hline 1994 & 3,9 & 1093,9 & 18,3 & 44,1 & $-0,1$ & 1,1 & 1,1 & $-2,2$ \\
\hline 1995 & 1,6 & 14,8 & 10,5 & 35,4 & $-0,5$ & $-5,0$ & $-0,3$ & $-1,4$ \\
\hline 1996 & 0,1 & 9,3 & 8,2 & 24,3 & $-1,9$ & $-3,8$ & $-1,1$ & $-1,5$ \\
\hline 1997 & 0,3 & 7,5 & 6,2 & 15,2 & $-1,5$ & $-4,3$ & $-1,4$ & $-1,4$ \\
\hline 1998 & 0,7 & 1,7 & 14,6 & 8,6 & $-1,4$ & $-7,5$ & $-1,0$ & $-1,0$ \\
\hline 1999 & $-1,8$ & 19,9 & 5,4 & 4,2 & $-1,7$ & $-10,0$ & $-1,0$ & $-3,8$ \\
\hline 2000 & $-0,9$ & 9.8 & 9.0 & 4.8 & -2.4 & $-4,6$ & $-3,6$ & $-4,1$ \\
\hline \multirow[t]{2}{*}{ Ano } & \multicolumn{4}{|c|}{ Dívida Pública/PIB² } & \multicolumn{4}{|c|}{ Transações Correntes/PIB } \\
\hline & Argentina & Brasil & Paraguai & Uruguai & Argentina & Brasil & Paraguai & Uruguai \\
\hline 1991 & 45,8 & 36,9 & 26,2 & 41,2 & $-0,3$ & $-0,3$ & $-5,2$ & $-0,1$ \\
\hline 1992 & 37,2 & 38,2 & 19,4 & 34,9 & $-2,4$ & 1,6 & $-0,9$ & $-1,9$ \\
\hline 1993 & 34,6 & 32,8 & 17,7 & 31,1 & $-3,4$ & $-0,1$ & $-0,9$ & $-2,9$ \\
\hline 1994 & 34,7 & 28,5 & 15,9 & 30,5 & $-4,3$ & $-0,3$ & $-3,5$ & $-2,3$ \\
\hline 1995 & 37,9 & 31,6 & 14,8 & 28,8 & $-1,9$ & $-2,6$ & $-3,1$ & $-1,1$ \\
\hline 1996 & 40,8 & 33,3 & 13,9 & 28,1 & $-2,4$ & $-3,0$ & $-5,2$ & $-1,1$ \\
\hline 1997 & 39,4 & 34,5 & 15,1 & 28,4 & $-4,1$ & $-3,8$ & $-2,5$ & $-1,3$ \\
\hline 1998 & 39,0 & 42,4 & 18,9 & 26,9 & $-4,8$ & $-4,3$ & $-1,7$ & $-2,1$ \\
\hline 1999 & 42,3 & 46,9 & 24,8 & 27,5 & $-4,3$ & $-4,6$ & $-1,8$ & $-2,9$ \\
\hline 2000 & 47,5 & 47,7 & 33,1 & 28,7 & $-3,2$ & $-4,1$ & $-1,4$ & $-3,0$ \\
\hline
\end{tabular}

Fonte: Elaboração própria com base em dados da CEPAL (www.cepal.org), Mercosul (www.mercosul.org) e Inter-American Development Bank (www.iadb.org).

Notas: (1) Déficit-superávit público: resultado primário mais resultado operacional mais resultado das empresas públicas. (2) Dívida pública inclui - quando for o caso - dívidas dos governos federal, estadual (estados ou províncias) e municipal. 